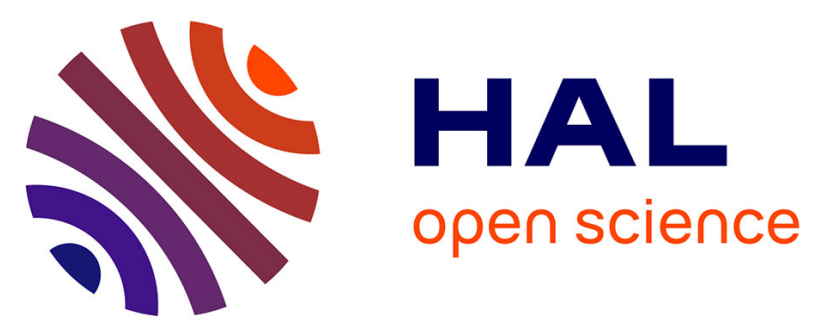

\title{
Palliative gastrectomy and other factors affecting overall survival in stage IV gastric adenocarcinoma patients receiving chemotherapy: A retrospective analysis
}

S. Sougioultzis, J. Syrios, I.D. Xynos, N. Bovaretos, C. Kosmas, J. Sarantonis, A. Dokou, D. Tzivras, G. Zografos, E. Felekouras, et al.

\section{To cite this version:}

S. Sougioultzis, J. Syrios, I.D. Xynos, N. Bovaretos, C. Kosmas, et al.. Palliative gastrectomy and other factors affecting overall survival in stage IV gastric adenocarcinoma patients receiving chemotherapy: A retrospective analysis. EJSO - European Journal of Surgical Oncology, 2011, 37 (4), pp.312. 10.1016/j.ejso.2011.01.019 . hal-00677317

\section{HAL Id: hal-00677317 https://hal.science/hal-00677317}

Submitted on 8 Mar 2012

HAL is a multi-disciplinary open access archive for the deposit and dissemination of scientific research documents, whether they are published or not. The documents may come from teaching and research institutions in France or abroad, or from public or private research centers.
L'archive ouverte pluridisciplinaire HAL, est destinée au dépôt et à la diffusion de documents scientifiques de niveau recherche, publiés ou non, émanant des établissements d'enseignement et de recherche français ou étrangers, des laboratoires publics ou privés. 


\section{Accepted Manuscript}

Title: Palliative gastrectomy and other factors affecting overall survival in stage IV gastric adenocarcinoma patients receiving chemotherapy: A retrospective analysis

Authors: S. Sougioultzis, J. Syrios, I.D. Xynos, N. Bovaretos, C. Kosmas, J. Sarantonis, A. Dokou, D. Tzivras, G. Zografos, E. Felekouras, E. Papalambros, N.

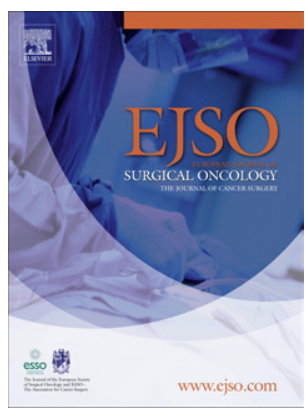
Tsavaris

PII: S0748-7983(11)00021-7

DOI: 10.1016/j.ejso.2011.01.019

Reference: $\quad$ YEJSO 3114

To appear in: European Journal of Surgical Oncology

Received Date: 14 June 2010

Revised Date: 16 December 2010

Accepted Date: 17 January 2011

Please cite this article as: Sougioultzis S, Syrios J, Xynos ID, Bovaretos N, Kosmas C, Sarantonis J, Dokou A, Tzivras D, Zografos G, Felekouras E, Papalambros E, Tsavaris N. Palliative gastrectomy and other factors affecting overall survival in stage IV gastric adenocarcinoma patients receiving chemotherapy: A retrospective analysis, European Journal of Surgical Oncology (2011), doi: 10.1016/ j.ejso.2011.01.019

This is a PDF file of an unedited manuscript that has been accepted for publication. As a service to our customers we are providing this early version of the manuscript. The manuscript will undergo copyediting, typesetting, and review of the resulting proof before it is published in its final form. Please note that during the production process errors may be discovered which could affect the content, and all legal disclaimers that apply to the journal pertain. 
Palliative gastrectomy and other factors affecting overall survival in stage IV gastric adenocarcinoma patients receiving chemotherapy: A retrospective analysis

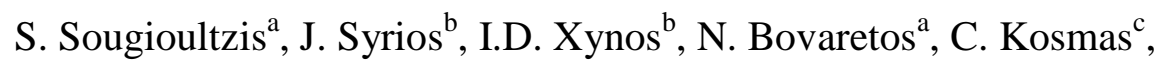
J. Sarantonis ${ }^{\mathrm{a}}$, A. Dokou ${ }^{\mathrm{b}}$, D. Tzivras ${ }^{\mathrm{a}}$, G. Zografos ${ }^{\mathrm{e}}$, E. Felekouras ${ }^{\mathrm{d}}$, E. Papalambros ${ }^{\mathrm{d}}$ and N. Tsavaris ${ }^{\mathrm{b} *}$

Author affiliations:

${ }^{\mathrm{a}}$ Gastrenterology Unit, ${ }^{\mathrm{b}}$ Oncology Unit, Department of Pathophysiology, ${ }^{\mathrm{d}}$ 1st Department of Surgery, "Laikon" University General Hospital, University of Athens, Athens, Greece

'2nd Department of Medical Oncology, "Metaxa" Cancer Hospital, Piraeus, Greece

e 3rd Department of Surgery, "G. Gennimatas" General Hospital, Athens, Greece

*Corresponding author: Nikolas Tsavaris, MD

Address for correspondence:

Medical Oncology Unit,

Department of Pathophysiology,

Laikon General Hospital,

Athens University School of Medicine,

11527 Athens, Greece

Phone: +30 2106463191

Fax: +302106463191

Email: tsavari1@ otenet.gr

Running header: Gastric cancer prognostic factors

Key words: prognostic factors, gastric carcinoma, palliative surgery, chemotherapy, survival 


\begin{abstract}
Objective: Most patients with gastric cancer present with locally advanced or metastatic disease and usually receive palliative therapy. We sought to identify factors influencing overall survival in patients with stage IV gastric cancer receiving palliative chemotherapy.
\end{abstract}

Patients and Methods: The records of 311 patients with histological diagnosis of gastric adenocarcinoma were retrospectively reviewed and 17 clinicopathological and therapeutic parameters were evaluated for their influence on overall survival.

Results: In multivariate analysis 9 factors were found to independently influence survival: no previous palliative gastrectomy [Hazard ratio (HR, 12; CI 7.96918.099)], single agent chemotherapy instead of combination chemotherapy (HR, 1.35; CI 1.068- 1.721), histological grade III (HR, 1.39; 95\% CI 1.098-1.782), the presence of hepatic (HR, 1.6; 95\% CI 1.246-2.073) and abdominal metastasis (HR, 1.33; 95\% CI 1.039-1.715), CA 72-4 > 7 U/L (HR, 1.39; 95\% CI 1.026-1.887), LDH> 225 U/L (HR, 1.72; 95\% CI 1.336-2.236], need for blood transfusions (HR, 1.58; 95\% CI $1.213-2.082)$, and weight loss $>5 \%$ (HR, 1.96; 95\% CI 1.352-2.853) at the time of initial diagnosis. Patients were stratified as low (0-2 factors), intermediate (3-6 factors) and high (7-9 factors) risk and the median survival was 76, 40 and 11 weeks, respectively.

Conclusion: Nine clinical and laboratory factors that adversely affect survival in patients with stage IV gastric cancer who receive chemotherapy were identified. Their concurrent presence seems to have an additive effect as patients with seven to nine factors have the worse prognosis. Palliative gastrectomy and combination chemotherapy appear to be associated with improved survival. 


\section{Introduction}

Gastric cancer is an aggressive tumour, posing the second leading cause of cancer specific mortality worldwide. Disease prevalence is higher in countries of northeast Asia (Japan, Korea, China), intermediate in Europe, South America and lower in North America, Australia and New Zealand. Overall survival in the United States, Europe and China is 20-25\%, however reported survival in Japan is better (52\%) which could be attributed to early detection through nationwide implementation of screening programs and optimized management[1]. In Greece, mortality rates from gastric cancer have been reported to be 10,9 and 5,8/ 10 5 for men and women, respectively[2].

Surgery is considered to be the most appropriate treatment for gastric cancer. However, the majority of gastric cancer patients present with locally advanced or metastatic disease, despite the progress in diagnostic modalities and curative resection is feasible in only $36 \%$ of cases; moreover, even patients with presumed resectable disease have relapse rates of 40-60\%[3]. Evidently, palliative treatment evolves as the primary management strategy for many gastric cancer patients. A number of trials have justified the use of palliative chemotherapy as compared to best supportive care to improve patient survival [4]. On the contrary, there is still insufficient evidence to recommend palliative gastrectomy in terms of survival benefit and therefore, the decision for surgery in current practice is individualized based on patient's clinical status and local surgical expertise, aiming at symptom relief and maintenance of patient's independence and function.

Given that chemotherapy and/or surgery could be associated with significant complications, there is a need to identify prognostic factors which may determine treatment response and survival in stage IV gastric cancer patients. Such an approach could refine palliative management according to the likelihood of clinical benefit. The aim of this study was to evaluate factors affecting survival in patients with stage IV gastric adenocarcinoma receiving palliative chemotherapy.

\section{Patients and Methods}

\section{Patients and data sources}

The medical records of 311 patients who received chemotherapy for histopathologically diagnosed stage IV gastric cancer between February 1997 and 
October 2007 were retrospectively reviewed. All were consecutive non-selected cases from a single Oncology Center and all patients were treated outside of clinical trials. Stage IV gastric cancer was defined based on American Joint Committee on Cancer (AJCC, $6^{\text {th }}$ edition) as $\mathrm{M}_{1}$ or $\mathrm{T}_{4} \mathrm{~N}_{1-3} \mathrm{M} 0$ [5]. Patients with Gastro-Esophageal junction tumors, lymphoma and squamous cell carcinoma were excluded. All patients included in the study had histological diagnosis of gastric adenocarcinoma and all demographic, clinical, imaging, laboratory and follow-up data were available. Metastatic disease was diagnosed by applying various imaging modalities, including chest X-ray, ultrasonography and computed tomography. Tissue specimens were obtained by gastroscopy, surgery, or fine-needle aspiration biopsy from liver lesions. 218 (70\%) had previously undergone palliative surgery (subtotal or total gastrectomy) at six different tertiary Greek hospitals where primary evaluation and surgical treatment was performed and further referral to the oncology centre initiated. The indications for palliative gastrectomy were judged individually by attending surgeons based on patients' general health, performance status, symptoms, extent of disease and feasibility of resection. Single-agent chemotherapy regimens were based on leucovorin modulated 5-Fluorouracil (5-FU, n=135). Combination chemotherapy regimens included combination treatments based on Irinotecan, Oxaliplatin and Capecitabine according to established protocols $(n=176)[4,6]$. These protocols evolved over time in accordance to internationally accepted standards and guidelines with respect to stage IV gastric cancer. The primary end point of the study was Overall Survival (OS). The study was approved by the Ethical Committee for Research Projects of Laiko Hospital, Athens, Greece.

\section{Prognostic variables}

17 putative clinicopathological and therapeutic prognostic variables were selected, based on factors identified by previous studies, as well as our own clinical experience[7-15]. Patient-related factors included age ( $\leq 60$ years or $>60$ years), gender, and pre-treatment performance status (PS) according to the Karnofsky Performance Status Scale Index. Tumor- related factors included symptoms including pain (yes vs. no), weight loss (no, $0-5 \%$, >5\%), and necessity for blood transfusions (yes vs. no); location of primary tumor (body vs. antrum), histological grading according the World Health Organisation (WHO) system, location of 
metastasis: Local invasion, lymph nodes, liver, lung, ovaries, bone abdomen/peritoneum; and biochemical parameters. For the latter, group categorizations were used: for carcinoembryonic antigen (CEA): normal $\leq 5 \mathrm{ng} / \mathrm{dl} v s$. elevated $>5 \mathrm{ng} / \mathrm{dL}$; for cancer antigen 19-9 (CA 19-9): values $\leq 30 \mathrm{U} / \mathrm{ml} v s$. $>30$ $\mathrm{U} / \mathrm{ml}$; for cancer antigen CA 72-4 (CA 72-4): normal $\leq 7 \mathrm{U} / \mathrm{ml} v$ s. elevated $>7 \mathrm{U} / \mathrm{ml}$; for C-reactive protein (CRP): normal $<5 \mathrm{mg} / \mathrm{dl} v s$. elevated $>5 \mathrm{mg} / \mathrm{dl}$; for Albumin normal $>3.4 \mathrm{~g} / \mathrm{dL} v s$. decreased $<3.4 \mathrm{~g} / \mathrm{dL}$; and for Lactate Dehydrogenase (LDH): normal $<225 \mathrm{U} / \mathrm{L} v$ s. elevated $>225 \mathrm{U} / \mathrm{L}$. Factors related to therapy included palliative gastrectomy (yes vs. no) and chemotherapy (single agent vs. combination chemotherapy).

\section{Statistical analysis}

Descriptive statistics were calculated with the use of mean, median and standard deviation for quantitative measurements and counts/percentages for discrete factors. Survival data were studied with the use of Kaplan-Meier method. Changes in survival between groups were recorded with the log-rank test. Prognostic models were established by searching all variables that significantly related OS at a level of $P$ values $\leq 0.05$ in the univariate analysis. Multivariate analysis was subsequently carried out using stepwise Cox proportional hazards modeling for OS. Best model selection for the factors that significantly affected OS factors were based on automated techniques. Results of regression analyses were displayed in the form of regression estimates tables. Hazard ratios (HRs) of outcomes under study were calculated for each parameter estimate as well as $95 \%$ confidence intervals. All categorical variables were compared using a baseline category as reference. All analyses were conducted at a 5\% significant level using SPSS v12.0 statistical package.

\section{Results}

\section{Patients}

311 patients with Stage IV gastric cancer were included in this analysis. The median age was 62 years (range: $30-74$ ) and the frequencies of the clinicopathological variables are shown in Table 1. Palliative surgery was performed in $70 \%$ of patients. All patients received chemotherapy; single agent and combination chemotherapy were administered in $43.5 \%$ and $56.5 \%$ of patients, respectively. 


\section{Overall Survival}

Survival data were collected for all patients. No patient was alive by the time of this analysis. The 1-year overall survival rate was $36 \%$. Based on the Kaplan-Meier method, the median survival time (MST) was recorded at 39 weeks (95\% CI 34- 44 weeks) (Figure 1).

\section{Univariate Analysis}

In univariate analysis the following parameters were found to adversely relate to survival (Table 2): Single agent chemotherapy $(\mathrm{P}=0.011)$, PS 60-70 $(\mathrm{P}<0.001)$, histology Grade III $(\mathrm{P}=0,033)$, presence of hepatic $(\mathrm{P}<0.001)$ and peritoneal/abdominal metastasis $(\mathrm{P}=0.009)$, need for blood transfusions $(\mathrm{P}<0.001)$, weight loss $>5 \%(\mathrm{P}<0.001)$, no previous palliative gastrectomy $(\mathrm{P}<0.001)$, albumin $<3.4$ g/dL $(\mathrm{P}<0.001), \mathrm{LDH}>225 \mathrm{U} / \mathrm{L}(\mathrm{P}<0.001), \mathrm{CRP}>5 \mathrm{mg} / \mathrm{dL}(\mathrm{P}<0.001)$, presence of pain $(\mathrm{P}<0.001)$, CA 19-9 >30U/ml $(\mathrm{P}=0.009)$ and $\mathrm{CA} 72-4>7 \mathrm{U} / \mathrm{ml}(\mathrm{P}=$ $0.007)$.

\section{Multivariate Analysis}

Factors that were found to be significantly related to OS were included in the multivariate analysis which is presented in Table 3.

\section{Hazard Ratios of Risk Factors}

9 prognostic factors were found to independently affect survival. 2 factors had a positive influence on survival including palliative gastrectomy and combination chemotherapy. In particular patients who had undergone palliative gastrectomy had 12 times lower probability of death compared with those who had no surgery and patients who had received combination chemotherapy had 1.35 lower probability of death compared to those received single agent chemotherapy. 7 factors were found to adversely affect survival including the presence of hepatic, abdominal/peritoneal metastasis (HRs 1.60 and 1.30 respectively), Grade III histology (HR, 1.40), CA 72-4 $>7 \mathrm{U} / \mathrm{L}(\mathrm{HR}, 1.39), \mathrm{LDH}>225 \mathrm{U} / \mathrm{L}(\mathrm{HR}, 1.72)$, weight loss > 5\% (HR, 1.96), and the need for blood transfusions at presentation (HR, 1.58). 


\section{Prognostic Grouping}

A prognostic grouping of the 311 patients was carried out according to the following criteria; low risk group: zero to two factors, intermediate risk group: three to six factors, high risk group: seven to nine factors and the corresponding survival curves are depicted in Figure 2. One year survival rates for low, intermediate and high risk patients were calculated at $71 \%, 33 \%$ and $0 \%$, respectively (Figure 2).

\section{Discussion}

We retrospectively analyzed data from 311 patients with Stage IV gastric adenocarcinoma who had undergone palliative chemotherapy. Our analysis demonstrated that factors associated with disease burden had a negative effect on survival. These included the presence of hepatic and abdominal/peritoneal metastasis, histological grade III, elevated CA 72-4 levels, elevated LDH levels and poor functional status at the time of initial presentation as indicated by weight loss $>5 \%$ and anemia necessitating blood transfusions.

\section{Prognostic significance of hepatic and abdominal/peritoneal metastasis}

Hepatic and abdominal/peritoneal metastasis have been shown previously to adversely affect survival in a multivariate analysis of a large cohort of patients with locally advanced and metastatic esophago-gastric cancer with an estimated hazard ratio of 1.41 and 1.33 respectively[7]; similar results were subsequently reported by others $[9,15]$.

\section{Prognostic significance of histological grading}

The various histological indexes commonly used for grading gastric cancer have been extensively investigated with regards to their prognostic potential with conflicting results[16,17]. The main difficulty in the histological classification of gastric cancer is the great variability of architectural and cytological features that may be present within the same tumor, hence, the prognostic significance of the various commonly used indexes for grading gastric cancer is rather controversial[18]. Nevertheless, our study supports the prognostic significance of the WHO histological staging as histology grades I, II and III were associated with progressively decreasing survival time (MST 50, 42 and 34 weeks respectively). 


\section{Prognostic significance of CA 72.4}

Tumor markers can be used clinically for monitoring of tumor recurrence as well as prognostic factors. Our results conform to previously published reports on the prognostic significance of CA 72-4 in Stage IV gastric cancer. Preoperative CA72- 4 levels have been shown previously to be more frequently elevated in patients with gastric cancer and lymph node $(\mathrm{P}=0.01)$, peritoneal $(\mathrm{P}=0.03)$ and liver involvement $(\mathrm{P}=0.001)$, being associated with a 3.8-fold higher risk of death by multivariate analysis[19]. The prognostic significance of CA 72-4 has been further highlighted by a sub- group analysis of patients with advanced gastric cancer (stages III and IV) in the study published by Louhimo et al.,(HR, 1.2)[12].

\section{Prognostic significance of LDH}

Our study reinforces the prognostic significance of elevated LDH levels, a well established prognostic indicator in terminally ill cancer patients [20].

\section{Prognostic significance of weight loss}

The etiology of weight loss at presentation in patients with gastric cancer is complex and poorly characterized and implies a physical wasting process, in excess of the degree of nutritional deficit. Decreased intake due to the anatomical location of tumor and cytokine induced anorexia may further aggravate the problem. The association of weight loss with poor survival, as well as with higher toxicity and lower chemotherapy response rates has already been described among patients with gastric cancer[21,22], similarly to the results presented in our study.

\section{Prognostic significance of blood transfusions}

The relationship between blood transfusions and survival in gastric cancer remains controversial. A previous study by Kampschoer et al. [23] showed no difference between 5-years survival rates in transfused and non-transfused patients grouped by stage and similar results were reported by others [24]. On the contrary, other reports, including an analysis of 1,710 patients with Stage III and IV gastric cancer by Hyung et al. showed that survival in transfused patients was clearly poorer than in nontransfused patients [25], which is in accordance to our findings.

\section{Prognostic significance of palliative gastrectomy}

Our study highlights the importance of palliative gastrectomy as a modality associated with improved survival. The value of palliative operations, including gastrectomy, in patients presenting with metastatic gastric cancer is still unsettled, since palliative gastrectomy was associated in some early studies with significant postoperative 
morbitity, prolonged hospital stay and poor quality of life[13]. Moreover, the indications and the type of the appropriate palliative surgical treatment in such patients are rather based on clinical judgment, local surgical expertise and patient's arguments than on data from controlled trials[26]. The rationale for offering palliative gastrectomy to patients with locally advanced or metastatic gastric cancer is to avoid tumor bleeding, perforation, obstruction, or complicated ascites and to possibly improve the outcome by reducing tumor burden, rendering the patients more responsive to adjuvant modalities. It has been postulated that tumor volume reduction diminishes the hypercatabolic state and may also confer immunological benefit by reducing the production of tumor derived immunosuppressive cytokines[14,27]. Although limited by a small number of patients Saidi et al. demonstrated a significantly better survival in gastrectomised patients who received adjuvant chemotherapy as compared with a chemotherapy only group $(\mathrm{P}=0.01$; mean survival 16.3 months versus 5.9 months). In their study the mortality and morbidity of palliative gastrectomy was $8.7 \%$ and $33.3 \%$ respectively, which was not statistically different from the mortality and morbitity following curative gastrectomy [14]. Similar results were obtained from subsequent analysis of larger cohorts demonstrating improved survival in patients with advanced gastric adenocarcinoma after palliative gastric resection, as compared to those who did not undergo the procedure[8-10]. In the current study, patients with previous palliative gastrectomy had clearly more favorable clinical course compared with those without gastrectomy (MST 53 vs. 16 weeks).

\section{Prognostic significance of combination chemotherapy}

Single agents used in the first line setting achieve only modest responses and are preferred for patients who are unable to tolerate combination chemotherapy[28]. Combination regimens are able to achieve better response rates at the expense of increased toxicity and are therefore preferred in appropriately selected patients. A meta-analysis comparing trials of systemic mono-therapy with those of multi-agent therapy, showed a significant increase in response with multi-agent therapy, with a hazard ratio of $0,83(95 \% \mathrm{CI} 0,74-0,93)$ and improvement in overall survival by about 1 month[4]. Nevertheless, no chemotherapy combination has been accepted as the gold standard in Stage IV gastric cancer. Both CF [cisplatin(CDDP/5)- 5-fluorouracil (5-FU)] and ECF (epirubicin-CDDP/5-FU) are seen as regimens of reference, but the median survival time (MST) does not exceed 7-10 months[29]. Options have 
expanded as it has been shown that capecitabine is at least as good as 5-FU and that oxaliplatin at least as good as cisplatin in these combinations[6]. In our study, 135 patients were treated with single agent chemotherapy (leucovorin modulated 5-FU while 176 patients had received combination chemotherapy and on multivariate analysis combination chemotherapy evolved as an independent prognostic factor for survival as compared to single agent chemotherapy (MST was 29 weeks for the single agent chemotherapy group and 45 weeks for the combination chemotherapy group, while 1- year survival was $29.6 \%$ and $45 \%$, respectively). These results further add to the accumulation of data from other studies suggesting a clear survival benefit when palliative gastrectomy is combined with postoperative chemotherapy $[11,14]$. In particular, Lin et al. have shown that the 1-year, 3-year and 5-year survival rate of stage IV gastric cancer patients who were treated with palliative gastrectomy and postoperative chemotherapy were $85.7 \%, 32.1 \%$, and $8.9 \%$, which were far better for those who were not; moreover, survival benefits were also apparent in patients with liver metastasis, peritoneal dissemination, and/or N3 lymph node metastasis if treated with this multimodality approach.

\section{Prognostic scoring system}

Prognostic scoring systems have been defined in several cancer types and are being increasingly used in clinics to stratify patients into different risk groups. The nine factors found by our analysis to independently affect survival in Stage IV gastric cancer were further evolved into a prognostic model which separates patients into three groups with distinct prognosis with 1-year survival rates for low, intermediate and high risk patients at $71 \%, 33 \%$ and $0 \%$, respectively.

\section{Study limitations}

The limitations of this analysis are the retrospective setting and the involvement of surgical teams from six different tertiary Greek hospitals in the surgical management of patients. Nevertheless, all surgeons were affiliated with the Medical School of the National and Kapodistrian University of Athens, practiced in hospitals with adequate case volume and, more importantly, applied similar therapeutic protocols/algorithms [30]. In addition, all patients were consecutive, non-selected cases, received chemotherapy treatment outside clinical trials, and were followed up by a single Oncology Center under the supervision the same oncology team which further addresses a real life situation. 


\section{Conclusions}

A number of factors may independently influence survival in stage IV gastric cancer patients. Factors associated with the severity of the disease such as the presence of hepatic and abdominal/peritoneal metastasis, histological grade III, elevated CA 72-4, elevated LDH and poor functional status at time of initial diagnosis as indicated by weight loss $>5 \%$ and anemia necessitating blood transfusions have a detrimental effect on survival. Therapeutic modalities such as palliative gastrectomy and combination chemotherapy appear to favor survival, although interpretation of data is restricted by the retrospective nature of the study and possible variability in the quality and the modality of the surgical procedures performed. In addition, it is anticipated that the prognostic model based on the above parameters will facilitate individual risk stratification and assist in the design of future prospective studies.

\section{Conflict of interest statement}

No conflicts of interest.

\section{Acknowledgements}

We thank Mr. Dimitrios Boulamatsis for performing the statistical tests.

\section{References}

1. Hartgrink HH, Jansen EP, van Grieken NC, van de Velde CJ: Gastric cancer. Lancet 2009;374:477-490.

2. Ong SH, Smithers MB: Gastric cancer in Australia. Gastric Cancer 2002;5:118-121.

3. D'Angelica M, Gonen M, Brennan MF, et al.: Patterns of initial recurrence in completely resected gastric adenocarcinoma. Ann Surg 2004;240:808-816.

4. Wagner $A D$, Grothe W, Haerting J, et al.: Chemotherapy in advanced gastric cancer: a systematic review and meta-analysis based on aggregate data. J Clin Oncol 2006;24:2903-2909.

5. AJCC: "Cancer staging manual." Springer, New York 2003.

6. Van Cutsem E, Van de Velde C, Roth A, et al.: Expert opinion on management of gastric and gastro-oesophageal junction adenocarcinoma on behalf of the European Organisation for Research and Treatment of Cancer (EORTC)-gastrointestinal cancer group. Eur J Cancer 2008;44:182-194.

7. Chau I, Norman AR, Cunningham D, et al.: Multivariate prognostic factor analysis in locally advanced and metastatic esophago-gastric cancer--pooled analysis from three multicenter, randomized, controlled trials using individual patient data. J Clin Oncol 2004;22:2395-2403. 
8. Hartgrink $\mathrm{HH}$, Putter $\mathrm{H}$, Klein Kranenbarg $\mathrm{E}$, et al.: Value of palliative resection in gastric cancer. Br J Surg 2002;89:1438-1443.

9. Kim JG, Ryoo BY, Park YH, et al.: Prognostic factors for survival of patients with advanced gastric cancer treated with cisplatin-based chemotherapy. Cancer Chemother Pharmacol 2008;61:301-307.

10. Lee J, Lim T, Uhm JE, et al.: Prognostic model to predict survival following first-line chemotherapy in patients with metastatic gastric adenocarcinoma. Ann Oncol 2007;18:886-891.

11. Lin SZ, Tong HF, You T, et al.: Palliative gastrectomy and chemotherapy for stage IV gastric cancer. J Cancer Res Clin Oncol 2008;134:187-192.

12. Louhimo J, Kokkola A, Alfthan $\mathrm{H}$, et al.: Preoperative hCGbeta and CA 72-4 are prognostic factors in gastric cancer. Int J Cancer 2004;111:929-933.

13. Ouchi K, Sugawara T, Ono H, et al.: Therapeutic significance of palliative operations for gastric cancer for survival and quality of life. J Surg Oncol 1998;69:41-44.

14. Saidi RF, ReMine SG, Dudrick PS, Hanna NN: Is there a role for palliative gastrectomy in patients with stage IV gastric cancer? World J Surg 2006;30:21-27.

15. Shiraishi N, Sato K, Yasuda K, et al.: Multivariate prognostic study on large gastric cancer. J Surg Oncol 2007;96:14-18.

16. Inoue K, Nakane Y, Michiura T, et al.: Histopathological grading does not affect survival after RO surgery for gastric cancer. Eur J Surg Oncol 2002;28:633-636.

17. Perrone G, Ruffini PA, Catalano V, et al.: Intratumoural FOXP3-positive regulatory $T$ cells are associated with adverse prognosis in radically resected gastric cancer. Eur J Cancer 2008;44:1875-1882.

18. Luebke T, Baldus SE, Grass G, et al.: Histological grading in gastric cancer by Ming classification: correlation with histopathological subtypes, metastasis, and prognosis. World J Surg 2005;29:1422-1427; discussion 1428.

19. Ucar E, Semerci E, Ustun H, et al.: Prognostic value of preoperative CEA, CA 19-9, CA 72-4, and AFP levels in gastric cancer. Adv Ther 2008;25:1075-1084.

20. Suh SY, Ahn HY: Lactate dehydrogenase as a prognostic factor for survival time of terminally ill cancer patients: a preliminary study. Eur J Cancer 2007;43:1051-1059.

21. Costa ML, de Cassia Braga Ribeiro K, Machado MA, et al.: Prognostic score in gastric cancer: the importance of a conjoint analysis of clinical, pathologic, and therapeutic factors. Ann Surg Oncol 2006;13:843-850.

22. Khalid U, Spiro A, Baldwin C, et al.: Symptoms and weight loss in patients with gastrointestinal and lung cancer at presentation. Support Care Cancer 2007;15:3946.

23. Kampschoer GH, Maruyama K, Sasako M, et al.: The effects of blood transfusion on the prognosis of patients with gastric cancer. World J Surg 1989;13:637-643.

24. Moriguchi S, Maehara Y, Akazawa K, et al.: Lack of relationship between perioperative blood transfusion and survival time after curative resection for gastric cancer. Cancer 1990;66:2331-2335.

25. Hyung WJ, Noh SH, Shin DW, et al.: Adverse effects of perioperative transfusion on patients with stage III and IV gastric cancer. Ann Surg Oncol 2002;9:5-12.

26. Cunningham SC, Schulick RD: Palliative management of gastric cancer. Surg Oncol 2007; 16:267-275.

27. Pollock RE, Roth JA: Cancer-induced immunosuppression: implications for therapy? Semin Surg Oncol 1989;5:414-419.

28. Wesolowski R, Lee C, Kim R: Is there a role for second-line chemotherapy in advanced gastric cancer? Lancet Oncol 2009;10:903-912. 
29. Cervantes A, Rosello S, Roda D, Rodriguez-Braun E: The treatment of advanced gastric cancer: current strategies and future perspectives. Ann Oncol 2008;19 Suppl 5:v103-107.

30. Damhuis RA, Meurs CJ, Dijkhuis CM, et al.: Hospital volume and post-operative mortality after resection for gastric cancer. Eur J Surg Oncol 2002;28:401-405. 
Table 1. Patient Characteristics

\begin{tabular}{|c|c|c|c|}
\hline & & $(n=311)$ & $(\%)$ \\
\hline \multirow[t]{2}{*}{ Age } & $\leq 60$ & 137 & 44.2 \\
\hline & $>60$ & 173 & 55.8 \\
\hline \multirow[t]{2}{*}{ Gender } & Male & 209 & 67.2 \\
\hline & Female & 102 & 32.8 \\
\hline \multirow[t]{3}{*}{ PS } & $60-70$ & 117 & 37.6 \\
\hline & 80 & 107 & 34.4 \\
\hline & $90-100$ & 87 & 28.0 \\
\hline \multirow[t]{2}{*}{ Pain } & No & 176 & 56.6 \\
\hline & Yes & 135 & 43.4 \\
\hline \multirow[t]{3}{*}{ Weight Loss } & No & 73 & 23.5 \\
\hline & $0-5 \%$ & 148 & 47.6 \\
\hline & $>5 \%$ & 90 & 28.9 \\
\hline \multirow[t]{2}{*}{ Blood Transfusion } & No & 183 & 58.8 \\
\hline & Yes & 128 & 41.2 \\
\hline \multirow[t]{2}{*}{ Tumor Location } & Body & 179 & 57.6 \\
\hline & Antrum & 132 & 42.4 \\
\hline \multirow[t]{3}{*}{ Histological Grade } & I & 14 & 4.5 \\
\hline & II & 179 & 57.6 \\
\hline & III & 118 & 37.9 \\
\hline \multirow[t]{7}{*}{ Metastasis } & Local invasion & 163 & 52.4 \\
\hline & Lymph nodes & 247 & 79.4 \\
\hline & Liver & 162 & 52.1 \\
\hline & Lung & 26 & 8.4 \\
\hline & Ovaries & 29 & 9.3 \\
\hline & Bone & 12 & 3.9 \\
\hline & Abdomen/Peritoneum & 151 & 48.6 \\
\hline \multirow[t]{2}{*}{ CEA } & $\leq 5 \mathrm{ng} / \mathrm{ml}$ & 158 & 50.8 \\
\hline & $>5 \mathrm{ng} / \mathrm{ml}$ & 153 & 49.2 \\
\hline \multirow[t]{2}{*}{ CA 19-9 } & $\leq 30 \mathrm{U} / \mathrm{ml}$ & 118 & 37.9 \\
\hline & $>30 \mathrm{U} / \mathrm{ml}$ & 193 & 62.1 \\
\hline \multirow[t]{2}{*}{ CA 72-4 } & $\leq 7 \mathrm{U} / \mathrm{ml}$ & 59 & 19.0 \\
\hline & $>7 \mathrm{U} / \mathrm{ml}$ & 251 & 81.0 \\
\hline \multirow[t]{2}{*}{ CRP } & $\leq 5 \mathrm{mg} / \mathrm{dL}$ & 165 & 53.1 \\
\hline & $>5 \mathrm{mg} / \mathrm{dL}$ & 146 & 46.9 \\
\hline \multirow[t]{2}{*}{ Albumin } & $>3.4 \mathrm{~g} / \mathrm{dL}$ & 171 & 55.0 \\
\hline & $<3.4 \mathrm{~g} / \mathrm{dL}$ & 140 & 45.0 \\
\hline \multirow[t]{2}{*}{ LDH } & $<225 \mathrm{U} / \mathrm{L}$ & 137 & 44.2 \\
\hline & $>225 \mathrm{U} / \mathrm{L}$ & 173 & 55.8 \\
\hline \multirow{2}{*}{$\begin{array}{l}\text { Palliative } \\
\text { gastrectomy }\end{array}$} & No & 93 & 29.9 \\
\hline & Yes & 218 & 70.1 \\
\hline \multirow[t]{2}{*}{ Chemotherapy } & $\begin{array}{l}\text { single agent } \\
\text { chemotherapy }\end{array}$ & 135 & 43.5 \\
\hline & $\begin{array}{l}\text { combination } \\
\text { chemotherapy }\end{array}$ & 176 & 56.5 \\
\hline
\end{tabular}

PS: performance status, CEA: Carcinoembryonic Antigen, CA 19-9: Cancer Antigen 19-9, CA 72-4:

Cancer Antigen 72-4, CRP: C-Reactive Protein, LDH: Lactate Dehydrogenase. 
Table 2. Univariate Analysis for Survival

\begin{tabular}{|c|c|c|c|c|c|}
\hline \multicolumn{3}{|l|}{ Variable } & \multirow{3}{*}{$\begin{array}{c}\text { MST } \\
39 \\
40\end{array}$} & $\begin{array}{c}\text { 1-year } \\
\text { survival } \\
\%\end{array}$ & $\begin{array}{c}\text { P- } \\
\text { value }\end{array}$ \\
\hline \multirow{2}{*}{\multicolumn{2}{|c|}{ Age }} & $\leq 60$ & & 37.2 & \multirow{2}{*}{0.536} \\
\hline & & $>60$ & & 34.1 & \\
\hline \multirow{2}{*}{\multicolumn{2}{|c|}{ Gender }} & Male & 40 & 35.4 & \multirow{3}{*}{0.728} \\
\hline & & Female & 36 & 32.4 & \\
\hline \multirow{2}{*}{\multicolumn{2}{|c|}{ Chemotherapy }} & single agent & 29 & 29.6 & \\
\hline & & $\begin{array}{l}\text { combination } \\
\text { chemotherapy }\end{array}$ & 45 & 45.0 & 0.011 \\
\hline \multirow{3}{*}{\multicolumn{2}{|c|}{ PS }} & $60-70$ & 21 & 16.2 & \\
\hline & & 80 & 48 & 44.9 & $<0.001$ \\
\hline & & $90-100$ & 55 & 50.6 & \\
\hline \multirow{3}{*}{\multicolumn{2}{|c|}{ Histological Grade }} & I & 50 & 35.7 & \multirow{3}{*}{0.033} \\
\hline & & II & 42 & 39.1 & \\
\hline & & III & 34 & 29.7 & \\
\hline \multirow[t]{14}{*}{ Metastasis } & \multirow[t]{2}{*}{ Local } & No & 41 & 37.2 & \multirow{2}{*}{0.409} \\
\hline & & Yes & 33 & 34.4 & \\
\hline & \multirow[t]{2}{*}{ Lymph nodes } & No & 36 & 21.9 & \multirow{2}{*}{0.110} \\
\hline & & Yes & 40 & 39.7 & \\
\hline & \multirow[t]{2}{*}{ Liver } & No & 50 & 47.7 & \multirow{2}{*}{$<0.001$} \\
\hline & & Yes & 28 & 24.7 & \\
\hline & \multirow[t]{2}{*}{ Lung } & No & 40 & 36.8 & \multirow{2}{*}{0.155} \\
\hline & & Yes & 30 & 23.1 & \\
\hline & Ovaries & No & 39 & 35.8 & 0715 \\
\hline & & Yes & 40 & 34.5 & 0.115 \\
\hline & Bone & No & 40 & 36.1 & 0.078 \\
\hline & & Yes & 17 & 25.0 & $0.0 / 8$ \\
\hline & Abdomen/P & No & 42 & 40.6 & \\
\hline & & Yes & 33 & 27.8 & 0.009 \\
\hline Blood Tran & sion & No & 53 & 50.3 & \\
\hline & & Yes & 21 & 15.6 & $<0.001$ \\
\hline Weight Lo & & No & 51 & 48.0 & \\
\hline & & $0-5 \%$ & 48 & 45.3 & $<0.001$ \\
\hline & & $>5 \%$ & 12 & 8.9 & \\
\hline Palliative & & Yes & 53 & 51.4 & $<0001$ \\
\hline & & No & 16 & 0.0 & $<0.001$ \\
\hline Albumin & & $>3.4 \mathrm{~g} / \mathrm{dL}$ & 50 & 46.2 & $<0.001$ \\
\hline & & $<3.4 \mathrm{~g} / \mathrm{dL}$ & 21 & 22.1 & \\
\hline LDH & & $<225 \mathrm{U} / \mathrm{L}$ & 57 & 51.8 & $<0.001$ \\
\hline & & $>225 \mathrm{U} / \mathrm{L}$ & 30 & 22.0 & \\
\hline CRP & & $\leq 5 \mathrm{mg} / \mathrm{dL}$ & 48 & 44.9 & $<0,001$ \\
\hline & & $>5 \mathrm{mg} / \mathrm{dL}$ & 24 & 25.3 & $<0.001$ \\
\hline Pain & & No & 45 & 43.2 & $<0.001$ \\
\hline & & Yes & 22 & 25.9 & $<0.001$ \\
\hline CA $19-9$ & & $\leq 30 \mathrm{U} / \mathrm{ml}$ & 48 & 42.4 & 0009 \\
\hline & & $>30 \mathrm{U} / \mathrm{ml}$ & 38 & 31.6 & 0.009 \\
\hline CA 72-4 & & $\leq 7 \mathrm{U} / \mathrm{ml}$ & 50 & 44.1 & 0.007 \\
\hline & & $>7 \mathrm{U} / \mathrm{ml}$ & 38 & 33.5 & \\
\hline CEA & & $\leq 5 \mathrm{ng} / \mathrm{ml}$ & 40 & 32.3 & 0359 \\
\hline & & $>5 \mathrm{ng} / \mathrm{ml}$ & 37 & 39.2 & 0.359 \\
\hline Location & Body & No & 40 & 34.9 & 0.454 \\
\hline
\end{tabular}




\section{ACCEPTED MANUSCRIPT}

\begin{tabular}{lllll}
\multirow{3}{*}{ Antrum } & Yes & 38 & 34.1 & \\
& No & 40 & 34.1 & 0.454
\end{tabular}

MST: median survival time, PS: performance status, LDH: Lactate Dehydrogenase, CRP: C-Reactive Protein, CA 19-9: Cancer Antigen 19-9, CA 72-4: Cancer Antigen 72-4, CEA: Carcinoembryonic Antigen 
Table 3. Multivariate Analysis of Survival

\begin{tabular}{|c|c|c|c|c|c|}
\hline & \multirow[t]{2}{*}{ P-Values } & \multirow[t]{2}{*}{ HR } & \multicolumn{2}{|c|}{$95.0 \% \mathrm{CI}$} \\
\hline & & & & Low & High \\
\hline \multicolumn{6}{|c|}{ Palliative Gastrectomy } \\
\hline \multirow{2}{*}{\multicolumn{2}{|c|}{$\begin{array}{l}\text { No vs. Yes } \\
\text { Chemotherapy }\end{array}$}} & 0.000 & 12 & 7.969 & \\
\hline & combination & 0.013 & 1.35 & 1.068 & 1.721 \\
\hline \multicolumn{6}{|c|}{ Liver matastasis } \\
\hline Yes vs. No & & 0.000 & 1.60 & 1.246 & 2.073 \\
\hline \multicolumn{6}{|c|}{ Abdominal/Peritoneal metastasis } \\
\hline \multirow{3}{*}{ 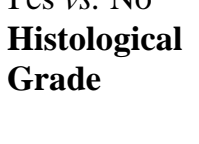 } & & 0.024 & 1.33 & 1.039 & 1.715 \\
\hline & Grade III $v s$. Grade I & 0.007 & 1.39 & 1.098 & 1.782 \\
\hline & Grade II vs. Grade I & 0.889 & 0.95 & 0.528 & 1.741 \\
\hline \multicolumn{4}{|l|}{ CA72-4 } & 1.026 & 1.887 \\
\hline \multicolumn{6}{|l|}{ LDH } \\
\hline \multirow{3}{*}{ Weight Loss } & & 0.000 & 1.72 & 1.336 & 2.236 \\
\hline & $>5 \%$ vs. $0-5 \%$ & 0.599 & 0.92 & 0.685 & 1.244 \\
\hline & $>5 \%$ vs. No & 0.000 & 1.96 & 1.352 & 2.853 \\
\hline \multicolumn{6}{|c|}{ Blood Transfusions } \\
\hline
\end{tabular}

HR: Hazard Ratio, CI: Confidence Interval, CA 72-4: Cancer Antigen 72-4, LDH: Lactate Dehydrogenase. 
Figure 1. Overall Survival (Patients with gastrectomy vs patients without gastrectomy)

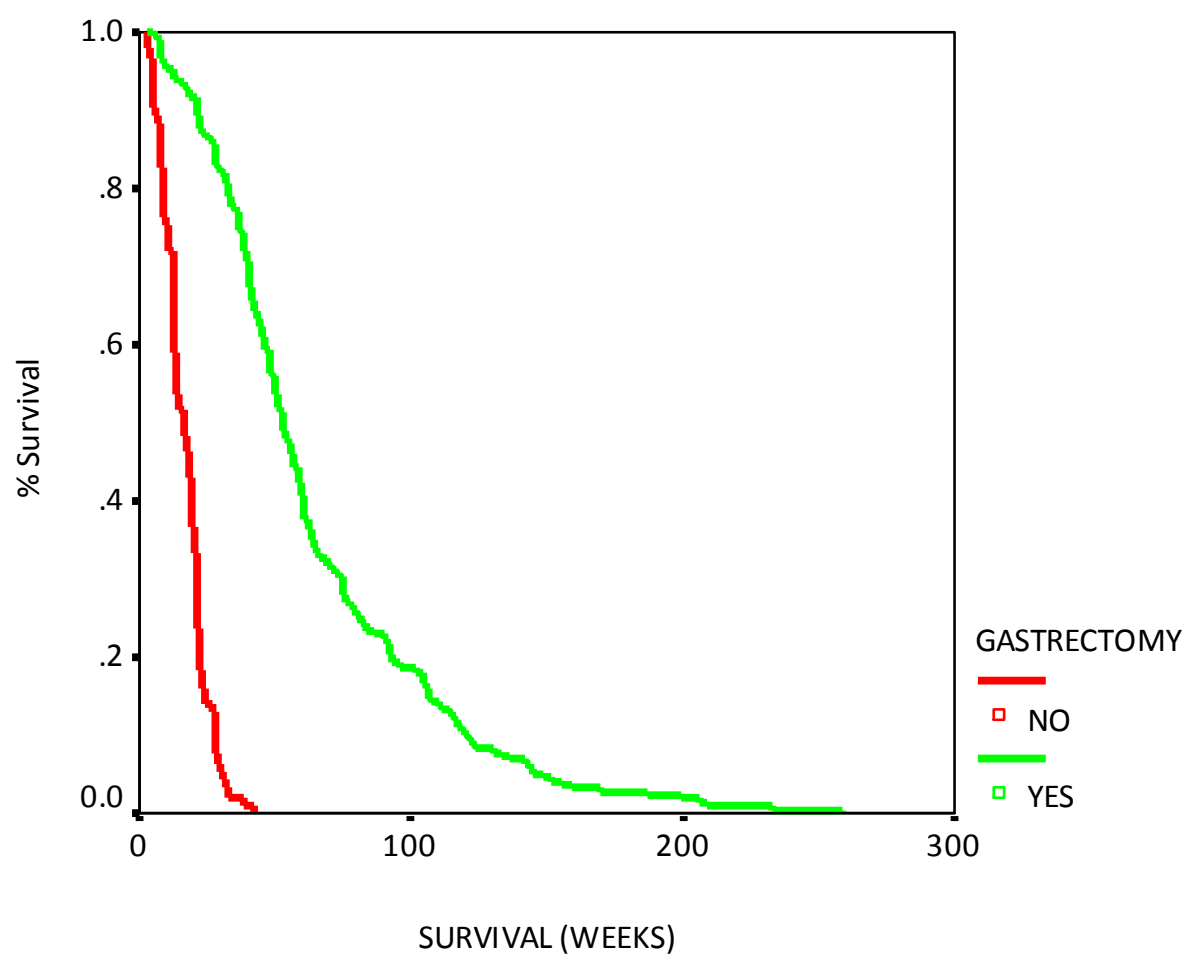


Figure 2.

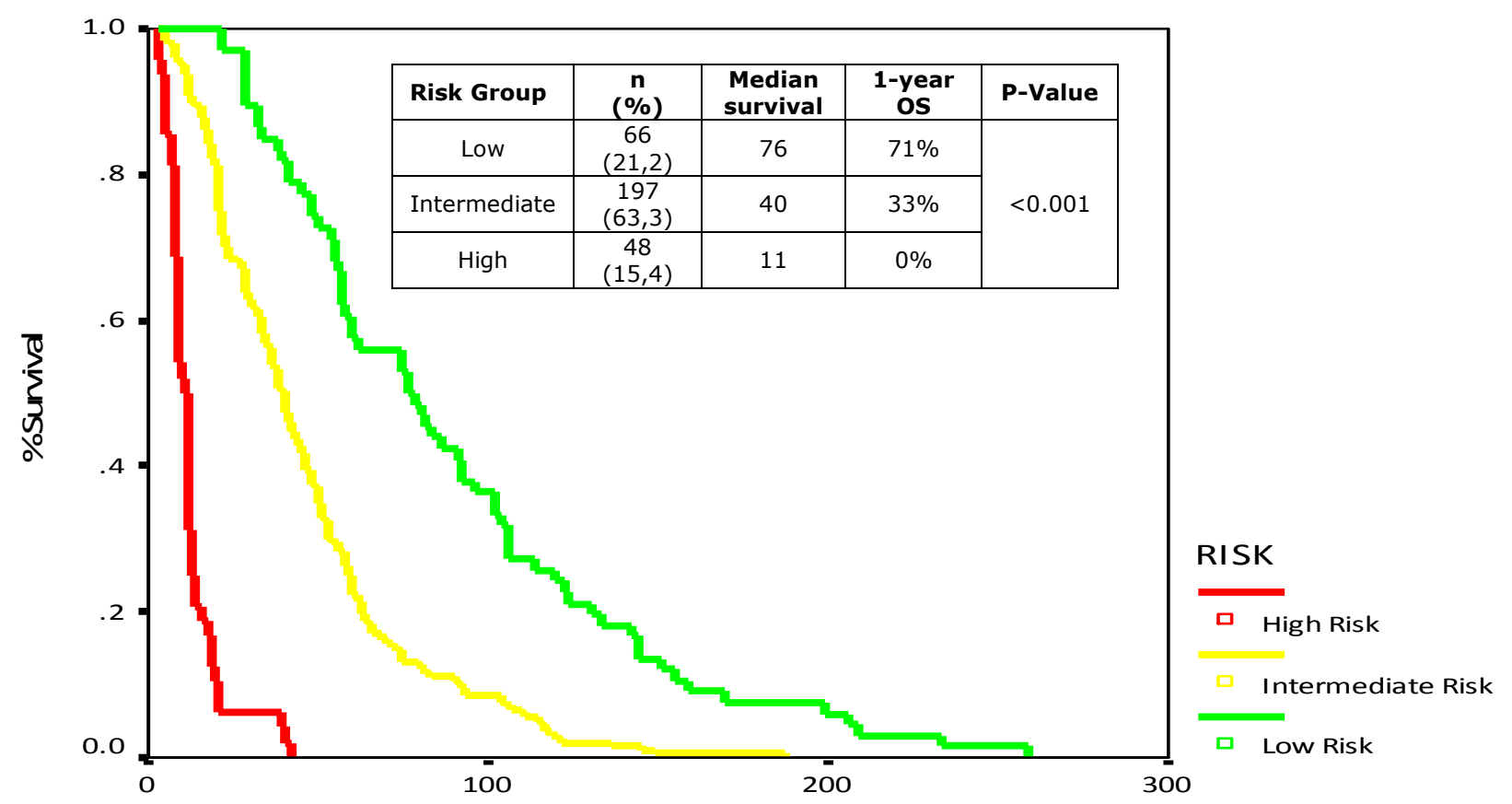

SURVIVAL (WEEKS) 